\title{
A Discourse Analysis of the Use of Code Switching in the Film Yellow Card
}

\author{
Clemenciana Mukenge \\ Department of Linguistics, University of Zimbabwe, Harare, Zimbabwe \\ E-mail: cmukenge@gmail.com
}

Advice Chimbarange (Corresponding author)

Department of Linguistics, University of Zimbabwe

P. O. Box MP 167, Mount Pleasant, Harare, Zimbabwe

Tel: 263-772-306-497/263-772-803-910Ｅ-mail: addie.chims@gmail.com

Received: August 2, 2012 Accepted: August 31, 2012 Published: December 1, 2012

doi:10.5296/ijl.v4i4.2929 URL: http://dx.doi.org/10.5296/ijl.v4i4.2929

\begin{abstract}
This study analyzes the use of code switching as a communication strategy in the film Yellow Card. The film Yellow Card deals with HIV and AIDS concerns and inevitable discusses issues pertaining to sex and sexuality, which are unspeakable in the public domain. This research reveals that code-switching is employed for the purposes of linguistic avoidance, whenever there is need to avoid a direct reference to the words and phrases considered taboo. It also occurs for intra-group identity where it functions as a communication technique for aligning or alienating interlocutors depending on the situations. Code switching is also employed to express concepts that can only be identified through a specific language and to create humour in different speech situations. Also revealed is the fact that code-switching is intra-language, occurring within the same language (formal and informal English), and inter-language, occurring between two languages (Shona and English). Critical Discourse Analysis (Fairclough, 1995) was used as both a theoretical guide and a methodological thrust. CDA views language as socially constituted and socially constituting. Data was gathered using in-depth textual analysis of the language content of the film Yellow Card and was presented in a descriptive manner. Data interpretation was carried out according to context of use. This study concludes that code-switching is a complex phenomenon that expresses a great deal more about the intentions and needs of the speaker or the writer. It is a crucial communication tool which is significant in sociolinguistics.
\end{abstract}

Keywords: Code switching, HIV and AIDS, Yellow Card 


\section{Introduction}

The film genre has been used extensively to campaign against HIV and AIDS in Africa. This paper analyses the language used in the HIV and AIDS film Yellow Card. This Zimbabwean film produced in 2000 discusses HIV and AIDS issues and code switching is one of the strategies used to convey awareness and prevention messages. In this film, code switching occurs within codes of the same language or between two different languages. HIV and AIDS talk generally deals with the subject of sex; a topic that is taboo in most African societies. Code switching plays a significant role in disguising topics that cannot be publicly addressed as interlocutors switch from one code to another to avoid candid talk about sex issues. Hence, language plays a crucial role in disseminating prevention messages as it embodies culture. Messages need to be encoded in a language that is sensitive and appropriate for the audiences. The objective of this study is to unravel how code switching is used as a communication strategy to talk about sex related topics in the public domain. This paper attempts to answer the following questions:

- What is the communicative function of code switching?

- Which forms of code switching are employed?

\section{Theoretical Frame Work}

The paper is guided by Critical Discourse Analysis (CDA) as its theoretical framework. Rogers (2004) views CDA as both a theory and a method. CDA according to Fairclough (1995) is a multidimensional method that views language use as socially constituted. Fairclough is of the view that language influences society and society influences language in turn.

\section{Methodology}

The paper utilizes the qualitative approach as its research design. The qualitative approach is a multi-method in focus, involving an interpretative, naturalistic approach to its subject matter (Denzin and Lincoln, 1994). This approach to research was found suitable for this study as it permits the researcher to analyze language as it occurs, using multi-qualitative methods to collect data. The sample of the study constitutes a video of the film Yellow Card. This film was selected because of its pioneering status as one of the first HIV and AIDS films in Zimbabwe produced in 2000 and is a multi international award winner. The language used to talk about HIV and AIDS in the initial campaign films tended to be discrete and implicit to avoid direct reference to issues related to the disease. Thus, Yellow Card, a film mainly composed of youthful characters, extensively employs code switching that includes a change from formal English to slang within sentences when discussing HIV and AIDS issues. This linguistic behavior is the focus of the study.

To collect data, this study relies on CDA method. This is a method of in-depth textual analysis that allows the researchers to analyze the words and phrases used by the characters in the chosen films within their specific contexts. Data is presented in a descriptive manner, describing the nature of language under study. It is from this data that the researchers deduced 
and conceptualized where and how code switching is used and to what effect in an interpretative manner. Interpretations where based on the context of language use. Thus, CDA is used as a vital theory in analyzing and interpreting data.

\section{Literature Review}

Code-switching is a well-known trait in the speech pattern of the average bilingual in any human society the world over including Zimbabwe. Most Zimbabweans either speak Shona and English or Ndebele and English. Thus, there is bound to be code switching determined by the context of language use. Several scholars have attempted to define code-switching. Hymes (1974) defines it as a common term for alternative use of two or more languages, varieties of a language or even speech styles. Bokamba (1989) views it as the mixing of words, phrases and sentences from two distinct grammatical systems across sentence boundaries within the same speech event.

According to Hoffman (1991), code switching is the situation in which two languages are used in the same utterance and Myers-Scotton (1993) defines it as a process in which there are alterations of linguistic varieties within the same speech act. Thus, a code refers to a variety within the same language and the entire system of a language. In this study, a code will be taken to mean a variety of language (e.g. slang or colloquial within Shona and English) and a language such as Shona and English languages used in Yellow Card.

Code switching can be viewed from a grammatical perspective, as well as from a sociolinguistic perspective (Van Dulm, 2007). Grammatically, there are three types of code switches. Hoffmann (1991) asserts that code switches can occur within sentences, (intrasentential code switching); between sentences, (intersentential) or at an extrasentential level which involves a situation in which a bilingual attaches a tag from one language to an utterance in another language. From a sociolinguistic perspective, there are two types of code switching, namely metaphorical and situational code switching (Van Dulm, 2007). According to Van Dulm, metaphorical code switching refers to the process in which a bilingual speaker changes codes because of the change in what is being talked about. In contrast to metaphorical code switching, situational code switching refers to the process in which a bilingual person often switches from one code to another depending on whom that person is talking to. (Van Dulm).

Code switching has both positive and negative effects on comprehension. According to Mati (2004), code switching between an African language and English enriches both the colloquial and the standard varieties of the receiving language. Code switching is also an identity marker. It consciously evokes a sense of cultural identity and unity; hence it is used as a direct and undeniable assertion of bilingual identity (Mahootian 2005). Code switching can be used to emphasize a point which the speaker feels could not be adequately asserted in one language or variety. Fishman (1972) notes that code switching may be related to class where speakers use a certain language with particular classes of speakers on particular occasions and topics.

According to Macnamara and Kushnir (in Heredia and Altribba et al. 2001: 165) one of the 
problems which arise out of code switching is that it is a time-consuming process which involves a bilingual switching from the grammar of one language or variety to another. Grosjean (1995) points out that another problem with code switching lies in the fact that if the code switched words are less frequently used in day to day speech they may be unintelligible to the monolinguals of that speech community. Auer (2009) supports this contention when he argues that words which are frequently used in the linguistic environment are preferred to those which are not. Grosjean (1995) further argues that various sources of knowledge such as the listener's knowledge of the world and the rules of the language also affect the recognition of words or codes. Thus, code switching as a linguistic style is either detrimental in terms of expressiveness in speech or is a vital tool for comprehension, depending on the situation.

There are various reasons why people code switch. Studies show that speakers may code switch in order to accommodate the person they may be speaking to. Sometimes speakers tend to adopt similar styles to reduce social distance. When this is done it reduces social distance between the speakers. Accommodation theorists argue that speakers use different varieties of language to express solidarity with or social distance from their interlocutors (Howard Giles et al, 1991). Le Page and Tabouret-Keller (1985) also posits that speakers may code switch as an act of identity marker where speakers seek to align themselves with, or distance themselves from, certain social groups. In other situations speakers adopt different styles to emphasize their distinctiveness or increase their social distance. This however, may be negatively evaluated by other speakers in communication events. This study analyses code switching patterns under the context of HIV and AIDS messages.

\section{Data Presentation}

Code-switching in the studied film exists between varieties of the same language (formal and informal English) and between two languages (English and Shona). In the selected film, it serves specific communicative functions which will be discussed later in this paper.

Code-switching in Yellow Card, occurs when the young generation discuss issues pertaining to HIV and AIDS and sex and sexuality. In most instances, there is a sudden shift from formal English to colloquial terms and phrases. When talking about women's buttocks, Skido and Tiyane immediately switch to slang words and either say 'butt' or 'bottom'. Referring to the act of sexual intercourse they resort to using the colloquial term pumping and sex in another instance is indirectly termed it.

There is also use of code-switching when the young characters switch from plain language into using complex speech such as idioms and sayings; metaphors and euphemisms. Metaphors are mostly used to refer to women bodies, their beauty and love relationships issues. The metaphor territory is a direct referent to a woman's body and angel is a metaphor of her beauty. The phrase my heart beats faster is used by Skido in place of being in love. Examples of euphemisms used by characters to refer to sex and sex organs within sentences include the following:

sleeping (referring to sex) 
bottom (buttocks)

wetting one's pants (act of urinating)

forced himself on me (raped me)

spell (STI-gonorrhea)

positive (having contracted HIV).

Seeing each other (having a sexual relationship)

He doesn't know know about girls yet. (He is not sexually active).

These euphemisms are thrown in as bits of speech in the conversation to replace the candid language of sex. Sayings are used in place of lengthy explanations of sexual phenomena, such as the following:

love at first sight.(fell in love instantly)

life is a lottery (Explaining the human fertilization process).

fangs of a girl and an appetite of a woman. (reference to sexual desire)

Code switching involving a complete shift from one language to another is also an aspect of purposeful language use in the film Yellow Card. A case in point is when Tiyane pays Juliet a visit at her posh home. The gardener and Tiyane shift between Shona and English. Tiyane switches to Shona to establish rapport with the gardener and shifts to English to accommodate Juliet's mother.

Juliet's mother: What's going on down there Shadreck?

Gardener: $\quad$ It's a black boy Madam

Tinaye: Saka blaz Imbwa iri kupi. Inoruma? (Well brother, where is the dog? Does it bite?)

Gardener: $\quad$ Inoruma ma bhoyi chete( It bites blacks only)

Tinaye: $\quad$ Saka ngeyi isingarume imi (Why doesn't it bite you )

Gardener: $\quad$ Yandi jairaka (It is used to me)

Juliet's mother: $\quad$ Sorry no jobs here.

Tinaye: $\quad$ Can I see Juliet?

\section{Discussions}

Linguistic investigations into the field of code-switching claim that factors that bring about the phenomenon of code-switching are numerous and extremely varied (Myers-Scotton (1993), Hymes (1974), Hoffman (1991). In this study, one of the main communicative functions of code switching as a style used in the studied film is linguistic avoidance. Linguistic avoidance is a response to stimulus that may be threatening to the speaker in a 
speech event. Janney (1999) defines linguistic avoidance as a

...complex, systematic, pragmatic skill involving choices in different linguistic systems (pronoun, determiner, person, aspect, modality, number, tense, voice, degree, negation etc) that modify meanings at different levels of linguistic organization (word, phrase, clause, sentence, discourse.).

Since Yellow Card focuses on HIV and AIDS and sex issues, it is the contention of this study that code switching is used when there is need to avoid directly referring to the words and phrases believed to be taboo in the Zimbabwean society. For instance, as described above, sex is referred to as 'sleeping around', or "pumping" and being sexually active is referred to as seeing the opposite sex. In addition, the findings show that being HIV positive is referred to as simple being positive. Openly talking about sex, illness or death and other misfortunes that befall people may be met with disapproval by society. In general, the Zimbabwean culture places restrictions on words and expressions which directly refer to these issues. Thus, a switch from ordinary language to euphemistic expressions within sentences or speech events is done first of all to save the face of the listener as Mashiri et. al (2002) put it. It also enables the speaker to avoid using explicit and offensive language in the face of the listening audience. The acceptability of the campaign messages partly depends on their sensitivity towards the values and norms of the target viewers. It is therefore paramount that culturally sensitive language is used to ascertain a degree of public acceptance of these messages.

Linguistic avoidance is linked to the Politeness theory (Leech, 1983). According to Leech), politeness refers to forms of behavior that humans adopt to maintain comity, or that create a general atmosphere of harmony. The use of euphemism, according to Leech's theory is thus a maxim of negative politeness that seeks to avoid discord rather than seek concord. Euphemism helps avoid those face threatening concepts that may cause discord in speech.

In some instances code-switching within the same language, as in the case of applying colloquial words and phrases within sentences, occurs for intra-group identity between the young characters. For instance, Tiyane and Skido largely use the slang words such as territory (woman's body), wetting my pants (urinating), pump (sex), etc as a way of identifying with each other. Whilst adult discourse utilizes euphemisms derived from cultural experiences, the youth use borrowed slang words and phrases to refer to and discuss HIV and AIDS and related issues. Code-switching here functions as a method of aligning speakers with others in specific situations, that is, defining oneself as a member of a group. The other possible explanation could be that code switching is done to express concepts that can be culturally identified through the appropriate language (Chung, 2006).

Colloquialism is a common linguistic behavior when it comes to young people in Zimbabwe. Thus, in a broader perspective, the use of slang in Yellow Card is a way to draw and engage the attention of young people in the larger society. Using their code assists in involving and merging them into the discussion of relationships, pregnancy and safe sex that are handled in the film. Their involvement and participation is crucial since they are the vulnerable and the target group of the HIV and AIDS campaign messages. Code-switching isideal in this case because, whereas the attention of the youths may be drawn by the occasional use of an 
informal variety, that of the wider audience is maintained by the consistent use of the formal code. In this way, the film appeals to a wider audience consisting of both the young and the elderly.

Code-switching from formal to slang or urban lingual is also employed to create humor. Humor is meant to bring about comic relief through laughter to lessen the burden of the intensity of the subject of HIV and AIDS that deals with intense issues such as illness and death. As Lederer (1997: 5) quoted in Mashiri et. al. (2002: 231) rightly argues 'slang allows us to break the ice and shift into a more casual and friendly gear'. For instance, when Skido, says 'I love that one with a big bottom" he creates a humorous effect. Bits of slang used in the body of formal language serve the purpose of attracting the attention of the viewers by means of hilarity, the idea being to laugh and learn. In the context of film, this approach assumes the edutainment mode of communication that simultaneously entertains and educate. It is a persuasive strategy to convince the people to listen, learn and maybe change their risky sexual behaviors that might expose them to the deadly pandemic.

Code-switching from one language to another serves different communication purposes. When used by two people it could be a way of claiming similar identity and as a tool for establishing rapport between the interlocutors. In the cited example, the young man Tiyane switches to Shona upon realizing that the gardener is black. In this scenario, Shona is used to claim the same ethnic identity with the gardener, thus easing communication barriers between the two. Initially there is tension between the two strangers but this is reduced when the two switch to Shona. In a similar study of code switching involving Asian Americans Adriane-Lo (1997) found that code switching was done to establish ethnic identity. Such incidents also bring the language of the film closer to reality as it mirrors the same situation as it is found in the society being represented. Although Tiyane speaks to Juliet and her mother in English, he reverts to Shona when conversing with the gardener. Code switching in this sense serves two different purposes; to accommodate an individual who is not competent in a certain language, as in the case of the gardener who has a low English proficiency. It is also a linguistic tool used to accommodate a wider Zimbabwean audience that speaks different languages which is the target of this film.

\section{Conclusion}

In this study, code-switching involves speakers switching from one language to another, that is, from English to Shona and vice versa. It also occurs from one variety of language to another where speakers switch between formal and informal codes of English. Code-switching occurs so as to effectively refer to and explain concepts that are difficult to talk about using the formal code, to create humor, to accommodate or exclude individuals or groups and to compensate for language deficiency in speech. Changing from one language or variety to another takes many forms associated with the mood of the speaker, circumstances of speech production or the interlocutors present. It can be argued, therefore, that code-switching is a complex phenomenon which is able to express a great deal more about the intentions and needs of the speaker and the writer. 


\section{References}

Auer, T.E. Jr. (2009). Spoken Word Recognition by Eye. Scandinavian Journal of Psychology, 50, 419-425. http://dx.doi.org/10.1111/j.1467-9450.2009.00751.x

Bokamba, E. (1989). Are there Syntactic Constraints on Code-Mixing? World Englishes, 8(3). http://dx.doi.org/10.1111/j.1467-971X.1989.tb00669.x

Chung, H. M. (2006). Code Switching as a Communication Strategy: A Case Study of Korean English Bilinguals. Bilingual Research Journal, 30, 293. http://dx.doi.org/10.1080/15235882.2006.10162878

Denzin, N. K., \& Lincoln, Y. S. (editors). (1994). Handbook of Qualitative Research. Thousand Oaks (CA): Sage Publications.

Fairclough, N. (1995). Critical Discourse Analysis. London: Longman.

Giles, H., Coupland, J., \& Coupland, N. (1991). Accommodation Theory: Communication, Context, and Consequence. In H. Giles, J. Coupland, and N. Coupland. (Eds.), Contexts of Accommodation. New York, NY: Cambridge University Press. http://dx.doi.org/10.1017/CBO9780511663673

Grosjean, F. (1995). A Psycholinguistic Approach to Code Switching: The Recognition of Guest Words by Bilinguals. In L. Milroy and P. Muysken (Eds). One Speaker, Two Languages: Cross-Disciplinary Perspectives on Code-Switching. Cambridge: Cambridge University Press. http://dx.doi.org/10.1017/CBO9780511620867.012

Heredia, R. R., \& J. Altarriba. (2001) Bilingual Language Mixing: Why Do Bilinguals CodeSwitch? Current Directions in Psychological Science, 10(5), 164-168. http://dx.doi.org/10.1111/1467-8721.00140

Hoffmann, C. (1991). An Introduction to Bilingualism. London: Longman.

Hymes, D. H. (1974). Foundations in Sociolinguistics: An Ethnographic Approach. Philadelphia: University of Pennsylvania Press.

Janney, R. W. (1999). The Whole Truth and Nothing but the Whole Truth. Linguistic Avoidance. In O. J. Simpson's Transcripts. London: ARNDT, Horst.

Le Page, R. B., \& Tabouret-Keller, A. (1985). Acts of Identity: Creole Based Approaches to Language and Ethnicity. London: CUP Archive.

Leech, G. N. (1983). Principles of Pragmatics. London: Longman.

Lo, A. (1999). Code-switching, Speech Community Membership, and the Construction of Ethnic Identity. Journal of sociolinguistics, $\quad 3, \quad 18-22$. http://dx.doi.org/10.1111/1467-9481.00091

Mahootian, S. (2005). Linguistic change and social meaning: Code switching in the media. $\begin{array}{lllll}\text { International of Journal Bilingualism, } & 9,\end{array}$ http://dx.doi.org/10.1177/13670069050090030401 


\section{Macrothink}

International Journal of Linguistics

ISSN 1948-5425

2012, Vol. 4, No. 4

Mashiri, P., Mawomo, K., \& Iom, P. (2002) Naming the Pandemic: Semantic and Ethical Foundations of HIV/AIDS Shona Vocabulary. (University of Zimbabwe Zambezia Journal 2002, XX1X, ii)

Mati, X. (2004). Using Code Switching as a Strategy for Bilingual Education in the Classroom. Paper presented at the 21st annual AEAA conference, 25-28 August. Cape Town, South Africa.

Myers-Scotton, C. (1993). Social Motivations for Code Switching. Evidence from Africa. Oxford: Clarendon Press.

Rogers, R. (2004). An Introduction to Critical Discourse Analysis in Education. London: Taylor and Francis.

Van Dulm, O. (2007). The Grammar of English-Afrikaans Code Switching. A Feature Checking Account. Doctoral Dissertation. Radboud University, Nijmegen.

\section{Copyright Disclaimer}

Copyright reserved by the authors.

This article is an open-access article distributed under the terms and conditions of the Creative Commons Attribution license (http://creativecommons.org/licenses/by/3.0/). 